\title{
São Benedito e Santa Luzia: manifestações de fé e identidade étnica*
}

\author{
Renata Maria TAmaso**
}

\begin{abstract}
Resumo: A presença da religiosidade na cidade de Espírito Santo do Pinhal/SP, descle sua fundação até os dias atuais, tem se mostrado elemento fundamental para a compreensão das relaçães étnicas em diferentes espaços sociais, territoriais e políticos. A religiosidade como manifestação socicoultural serviu como meio para que grupos étnicos diversificados se colocassem nos espaços político, social e cultural local. Além disso, também serviu de elemento de inclusão ou exclusão no espaço urbano da cidade. As Igrejas de São Benedito e Santa Luzia são dbis lugares representativos das práticas sociais relacionadas aos negros, afrotbrasileiros e italianos na cidade de Pinhal. Ar seja, tais lugares são aqui analisadbs como signos identitários. Por meio deles e das manifestaçães que neles se deram, buscamos analisar as "táticas", "estratégias" e "práticas" utilizadas por diferentes grupos étnicos para não só consolidar seu lugar na cidade, mas, scbretudb, como reafimação de sua identidade.
\end{abstract}

Palavras-chave: religiosidade; sagradb; profano; identidade étnica; manifestaçães aultur rais.

Espaço de múltiplas trocas, de tantas leituras $e$ de tantas funções politicas e religiosas, a festa e o seu calendário transformam-se, no período colonial, na ponte simbólica entre o mundo profano e o mundo sagrado. M ARY Del Priore, 2000, p. 27)

A presença da religiosidade na cidade de Pinhal é um elemento significativo para aqueles que se ocupam de estudar as religiões e suas manifestações. Objetos profícuos, os espaços (igrejas) e as manifestações que nele são "experienciadas"1 (as festas) mostraram-se importan-

\footnotetext{
* Este artigo faz parte das reflexões presentes em minha pesquisa de doutoramento defendida no Programa de PósGraduação em História (Unesp/Assis) e da monografia de especialização em Planejamento e Marketing Turístico apresentada ao Senac/Águas de São Pedro, no ano de 2005. Para mais detalhes ver: Tamaso, R., 2005a e 2005b.

** Mestre e doutora em História - Unesp/Assis. Especialista em Planejamento e Marketing Turístico - Senac/Águas de São Pedro. Professora na UFG (CEPAE). E-mail: renatamaria@uol.com.br ou retamaso@cepae.ufg.br

1. O conceito de experiência é usado por Tuan (1983) para pensar lugar. Para esse autor: "Experienciar é vencer os
}

tes momentos para a compreensão das relações entre as diversas etnias, ${ }^{2}$ diversos grupos, em espaços sociais, territoriais e políticos também diversos.

Segundo Roberto V. Martins (1986, p. 371), em 1906, Espírito Santo do Pinhal possuía onze capelas ou igrejas católicas em funcionamento, ${ }^{3}$

perigos. A palavra 'experiência' provém da mesma raiz latina (per) de 'experimento', 'experto' e 'perigoso'. Para experienciar no sentido ativo, é necessário aventurar-se no desconhecido e experimentar o ilusório e o incerto. Para um experto, cumpre arriscar-se a enfrentar os perigos do novo" (Tuan, 1983, p. 10).

2. A noção de etnicidade à qual recorremos está diretamente vinculada à dinâmica social. Seu conteúdo tanto quanto sua significação "são suscetíveis de transformações e de redefinições". Ou seja: "[...] a etnicidade não se define como uma qualidade ou uma propriedade ligada de maneira inerente a um determinado tipo de indivíduo ou de grupo, mas como uma forma de organização ou um princípio de divisão do mundo social cuja importância pode variar de acordo com as épocas e as situações" (Poutignat/ Streiff-Fenart, 1998, p. 125).

3. Lista de capelas de Espírito Santo do Pinhal, organizada por Wanderley dos Santos, da Cúria Metropolitana de São Paulo. In: Martins, 1986, p. 371. 
quais sejam: Capela do Espírito Santo da Aparecida, Capela de Nossa Senhora das Brotas, Capela de Nossa Senhora da Conceição Aparecida, Capela de Nova Louzã e Oratório (Fazenda), Capela de Santa Cruz, Capela de Santa Cruz da Boa Vista (Fazenda), Capela de Santo Antônio do Jardim (Distrito), Capela de São Benedito, Capela de São Benedito do Morro Grande (Fazenda) e Irmandade da Matriz.

A forte presença da religião católica em Pinhal aparece em textos de memorialistas e periódicos locais e atestam a importância da religiosidade no cotidiano dos moradores da cidade e regiões circunvizinhas. Obras e reformas em igrejas, festas e procissões, programas e propagandas são temas normalmente encontrados nesses documentos que surgem em fins do século XIX e perpassam as primeiras décadas do século XX.

Tais documentos comprovam como diversos grupos sociais organizavam-se em seus bairros e realizavam festas em homenagem aos santos padroeiros, muitas vezes com o objetivo de angariar fundos para a construção de uma capela em seu louvor.

Os artigos publicados no Diário de Campinas entre 1886 e 1889 e reunidos por Ernesto Rizzoni (s/d) comprovam a existência - em fins do século XIX - de inúmeras festas em louvor a santos padroeiros, não apenas nos espaços urbanos da cidade, como também nas fazendas da região. Entre as que tiveram mais destaque estão: do Divino Espírito Santo, de São Benedito, Nossa Senhora Aparecida, São Sebastião, Nossa Senhora das Brotas e Santa Cruz.

O significado que essas festas foram adquirindo ao longo do tempo para as diversas comunidades étnicas - como negros e afrobrasileiros, italianos, espanhóis etc. - é um fator a ser analisado com cuidado, pois, além de serem compreendidas como a própria manifestação de fé, são representações de tradições vindas juntamente com a chegada desses grupos em fins do século XIX, na cidade de Pinhal.

Cabe lembrar que, entre as décadas de 1890 e 1910, a cidade vivia o êxodo rural provocado pela libertação dos escravos e a conseqüente onda migratória que introduziu no espaço urbano aproximadamente mil imigrantes italianos (Tamaso, 1997, p.179). Nesse momento, coube aos órgãos competentes - representados por uma elite dominante branca (luso-brasileira) - organizar os espaços da cidade, incluindo ou excluindo aqueles que julgavam "impuros", "menores", "inferiores" etc (Chalhoub, 1990, p.17).

Os estudos sobre o papel das instituições de poder, como o Estado e a Igreja, na normatização e ordenação de manifestações populares nos espaços públicos - praças e igrejas comprovam o quanto tais instituições "imiscuíram-se" nesses espaços com o intuito de "remoldá-lo à sua imagem e semelhança" (Del Priore, 2000, p. 90).

Para Mary Del Priore (2000, p. 94), o Estado moderno empenhou-se em modificar os códigos culturais que proviam dos tempos coloniais. Da mesma forma, a Igreja, por meio do Concílio de Trento, também teve a mesma preocupação. Assim, as festas - acompanhadas de danças, cantos, gestos, vestimentas, jogos e bailes - eram consideradas "fora de ordem".

Em um momento de grandes transformações políticas e econômicas, tornava-se imperativo organizar e normatizar os espaços sociais na cidade (Del Priore, 2000, p. 104). Em Pinhal, assim como em grande parte das cidades brasileiras, foi acionado um código de posturas para que tais espaços fossem delimitados, a fim de cumprir com um ideal maior de "ordem e progresso".

A normatização e a disciplinarização das condutas na sociedade foram instrumento essencial para a manutenção do poder do Estado e da Igreja. Foram "estratégias" utilizadas como "instrumento de demandas institucionais". Todavia, tais estratégias muitas vezes foram sobrepujadas por "táticas" constituídas por grupos variados para subverter a ordem estabelecida oficialmente.

Segundo De Certeau (1994, p. 46), o ato de planejar implica saber, pensar e articular formas de transformar o espaço social em um espaço próprio. É o que denomina de "um próprio", munido de normas e regras, que constitua um "sujeito universal e anônimo que é a própria cidade" e que se caracteriza pelas "estratégias" de ação de determinado grupo em um determinado espaço. Tais atos representam as estratégias que servirão de base para a gestão 
das relações de um grupo dominante - a elite luso-brasileira - com uma exterioridade distinta - os negros e italianos em Pinhal.

Por outro lado, o que não pode contar com um próprio, De Certeau (1994, p. 46) denominou de "táticas". De acordo com ele, onde as táticas se constituem "[...] proliferam-se as astúcias e as combinações de poderes sem identidade, legível, sem tomadas apreensíveis, sem transparência racional - impossíveis de gerir". É o que o historiador chama de "o retorno das práticas": são elas que tecem as condições determinantes da vida social (De Certeau, 1994, p. 174).

Nessa perspectiva, o que não se insere nesse espaço está fora. E o que está fora é "o lugar do outro", ou seja: as "táticas". Ora, se considerarmos o espaço urbano construído pelos luso-brasileiros como "um próprio", ou seja, como "estratégias", devemos considerar os espaços construídos pelos ítalo e afro-brasileiros na cidade de Pinhal como espaço "do outro", ou seja, o espaço onde inserem-se as "táticas" (De Certeau, 1994, p. 46).

Para entendermos melhor como funcionam as "estratégias" utilizadas pelas instituições de poder (elite branca e Igreja) na cidade de Pinhal e, no seu verso, as "táticas" desenvolvidas por grupos específicos - negros, afro-brasileiros e italianos -, devemos deitar os olhos sobre a construção de signos caros a esses grupos, como as Igrejas de São Benedito e Santa Luzia e as manifestações aos respectivos santos.

A religiosidade, como manifestação sociocultural em Pinhal, serviu de elemento de aglutinação ou de exclusão de determinados grupos no espaço urbano da cidade, determinando poderes e organizando espaços ${ }^{4}$ (Tamaso, 2005a, p. 83). Portanto, deve ser analisado como um fator político deveras significativo para a sustentação do status quo de determinados grupos sociais e étnicos locais.

Os locais destinados ao sagrado, ou seja, as igrejas, foram ocupando espaços na paisa-

\footnotetext{
4. Em texto da sessão da Câmara Municipal de 2 de junho de 1887, encontra-se referência clara a um código de posturas que era utilizado nas cidades como maneira de organizar a ocupação das terras, o tamanho e a localização das propriedades, largura de calçamento etc. O texto demonstra a preocupação com o cumprimento do código e a necessidade de demolir "uma pequena casinha" que existia no centro do "novo Largo de Nossa Senhora Aparecida". Livro de Ata das Sessões da Câmara Municipal referente ao ano de 1887.
}

gem urbana e confirmando a forte presença da religião católica na cidade. Quando falamos em sagrado, estamos nos referindo não apenas ao culto a imagens de santos - prática comum destinada a atribuir caráter de santidade por meio de cerimônias religiosas -, já que isto é bastante relativo, considerando que, para cada religião ou crença, pode existir um objeto sagrado, e este deve ser analisado inserido em uma lógica própria àquela cultura.

Entendemos o espaço sagrado, como nos propõe Émile Durkheim (1989, p. 373), como o lugar destinado à vivência religiosa. Entretanto, para ele, esta não pode "coexistir no mesmo espaço" que a profana, nem nas "mesmas unidades de tempo". É preciso, portanto, arranjar lugar para que a vida religiosa possa se desenvolver e destinar-lhe "dias ou período determinados dos quais todas as ocupações profanas sejam eliminadas". E conclui: "assim surgiram as festas".

Ou seja, o espaço sagrado do qual falamos deve ser entendido em uma abordagem antropológica, em que signos culturais são construídos e manifestam-se de forma específica em cada cultura. A maneira como esse espaço (sagrado) é apropriado nas diferentes sociedades encontra-se diretamente ligada à forma pela qual as instituições de poder normatizam e ordenam a vida cotidiana da sociedade (Del Priore, 2000).

Estudar tais espaços e as manifestações que neles se deram é adentrar em um microcosmo das relações sociais de tal forma a desvendálas (pelo menos em parte) em suas mais significativas tradições e memórias. Pois, da sua preservação, depende a manutenção da identidade cultural desses grupos.

\section{O Largo de São Benedito: lugar de negros e afro-brasileiros}

A região do Largo de São Benedito começou a ser habitada por volta de 1890 , quando o centro da cidade passou a sofrer o impacto do desenvolvimento da cultura cafeeira e, conseqüentemente, do desenvolvimento urbano. Essa região encontrava-se localizada em uma área de fácil acesso à saída para o Sertãozinho, bairro rural que reunia muitas fazendas e de onde, provavelmente, teriam vindo alguns negros. 
Como os espaços luso-brasileiros já haviam sido demarcados, cabia, à elite dominante, determinar quais as áreas onde outros grupos étnicos poderiam habitar. Tal região foi o lugar escolhido pelo grupo, política e economicamente dominante, para a fixação dos negros e seus descendentes no espaço urbano. Quanto aos italianos, estabeleceram-se em sua maioria nas regiões de acesso à cidade, em ruas normalmente destinadas ao comércio e no Bairro de Santa Luzia, como veremos adiante.

O Largo de São Benedito e imediações levou, aproximadamente, trinta anos para que fosse todo habitado. Acreditamos que o marco desse desenvolvimento tenha ocorrido com a mudança do cemitério para outra área, em 1888, $\mathrm{e}$, conseqüentemente, com a construção da igreja, a partir de 1903.

A história da construção da igreja é narrada por d. Maria Tereza de Filippi: " "Uma irmandade de pretos tomou a peito a construção da Capela", datando este fato "mais ou menos de 1900 e início de 1901".

Em artigo datado de 18 de abril de 1888, encontra-se uma nota sobre a Irmandade São Benedito, que acabara de ser fundada pelos "homens de cor residentes na cidade", "pretendendo mais tarde erigir-lhe uma capela e cemitério". O autor desconhecido que o assinou com as iniciais M.J. destacou a importância de esses homens serem "auxiliados em tão piedoso fim", dizendo: "Não deixem eles esmorecer a iniciativa que tomaram" (apud Rizzoni, s/d, p. 109). ${ }^{6}$

$\mathrm{O}$ fato de a data da fundação dessa irmandade (18/4/1888), formada por homens de côr, ter ocorrido tão próxima da data da abolição dos escravos na cidade de Pinhal (que ocorreu em 16 de abril de 1888) leva a pensar que os negros já estavam se organizando anteriormente. Muitos estudos confirmam o aparecimento de inúmeras entidades e grupos de solidariedade

5. Relato escrito fornecido por d. Maria Tereza de Filippi, memorialista local, no percurso da minha pesquisa de doutoramento. In: Tamaso, 2005a.

6. Acredito que a informação fornecida por d. Maria Tereza tenha sido extraída da mesma fonte que utilizamos. O que sugere que este é o primeiro momento em que obtive um dado, mesmo que não oficial, sobre a Igreja de São Benedito. A partir daí, foram encontradas apenas notícias sobre as festas em seu louvor nos artigos dos jornais de época consultados. In: Tamaso, 2005a. que se formaram entre indivíduos de uma mesma etnia. ${ }^{7}$ Tais grupos e entidades representavam a forma com que diversas etnias reforçavam sua identidade no espaço urbano (Lesser, 2001). ${ }^{8}$

Esses elementos são significativos, pois ajudam-nos a refletir sobre as possíveis razões que teriam levado os negros a edificar espaços próprios, não apenas de sociabilidade como a construção de suas habitações no Largo de São Benedito, mas, principalmente, símbolos próprios de identidade, como a igreja e o Clube Bangú.

Em documento pesquisado na Cúria Metropolitana de São Paulo, de 11/12/1900, o genealogista Roberto V. Martins (1986) encontrou uma solicitação para "Provisão de ereção da Capela sob a invocação de São Benedito" no distrito da paróquia. Esta foi endereçada ao responsável pela igreja na província de São Paulo pelo sr. Joaquim José do Nascimento. ${ }^{9}$

Em 10 de julho de 1903, deu entrada uma solicitação para "Provisão de licença para a Celebração de uma Missa na Capela de São Benedito", e em 5 de setembro de 1904, encontramos outra solicitação para "Provisão de 5 anos com as faculdades do estilo para a Capela de São Benedito". Ambos os pedidos foram feitos pelo pároco da cidade, pe. Landell de Moura.

7. Em Pinhal, em 1889, foi fundada a Sociedade de Mútuo Socorso Dante Alighieri e a Sociedade Espanhola. A Sociedade Recreativa também funcionava como lugar de reuniões políticas e culturais dos luso-brasileiros, elite política da época, por isso mesmo foi chamada de "Senadinho". In: Tamaso, 1998; Rizzoni, s/d.

8. Em estudo sobre a imigração não-européia para o Brasil - especificamente, japoneses e sírio-libaneses -, Lesser alertou para o fato de os imigrantes não ficarem apáticos às formas de exclusão efetuadas pelas elites dominantes locais. Segundo ele, "[...] enquanto a ideologia se metamorfoseava em política, aqueles a quem a entrada era negada se tornaram tão importantes quanto os que conseguiam entrar" (Lesser, 2001, p. 26). Ou seja, a diferença encontrava-se não apenas entre o que era aceitável e o que não era, mas também entre os que eram de dentro e os que eram de fora, os que eram brancos e os que não eram. Tais categorias eram utilizadas das mais diferentes formas, nos mais diferentes momentos, para explicar os mais diferentes atos. Sobre isso ver também: Kathryn Woodward, 2000, p. 9.

9. In: Registro de Provisões de 1892-1895 da Cúria Metropolitana de São Paulo, 19-2-4, fls. 106 (apud Martins, 1986, p. 345). Sabemos, pelos depoimentos e jornais de época analisados, que se trata de uma pequena capela onde, esporadicamente, eram rezadas missas pelo padre Landell de Moura, responsável pela paróquia local, com autorização do bispo da província (Martins, 1986, p. 347). 
As solicitações datadas de 1903 e 1904, apesar de não fornecerem a data exata da fundação da igreja, confirmam a existência da capela e sua atividade já nesse período. Dessa forma, consideramos a data do requerimento de 11 de novembro de 1900 como a que marca o início de sua construção e a data de 10 de julho de 1903 como a de sua abertura para as atividades religiosas.

Com relação às obras de construção da igreja, segundo relato de d. Maria Tereza de Filippi, quem coordenava os trabalhos "era um preto chamado Leopoldo, que era pedreiro e tinha vindo do Rio de Janeiro". No lançamento da pedra fundamental, "houve banda de música, missa campal e bênção".

De acordo com ela, muitas festas e leilões foram realizados a fim de angariar fundos para a construção da capela. Nessas festas, os negros dançavam "as tradicionais danças do 13 de maio", em comemoração à abolição da escravatura e, nesse mesmo dia, "a igreja foi inaugurada com festas, leilões e procissão".

A Igreja de São Benedito existe até hoje. Seu prédio passou por inúmeras reformas desde a década de 1930 até a década de 1950: sua fachada foi modificada, foram colocados os atuais altares de madeira, fabricados por Nino Françoso (ítalo-brasileiro) e foi construído um muro e uma escadaria para facilitar o acesso à igreja.

Atualmente, a igreja não conta com o muro que foi retirado (por volta da década de 1970) e nem mesmo a imagem de São Benedito exposta no altar é a mesma. A antiga foi retirada pelo monsenhor Augusto Alves Ferreira - responsável maior pela Igreja local - e levada para a Igreja Matriz. Esse tema será abordado posteriormente.

\section{O Bairro de Santa Luzia: lugar de italia- nos e ítalo-brasileiros}

A Igreja de Santa Luzia localiza-se no bairro rural de mesmo nome, na cidade de Pinhal. A região onde este se situa era conhecida - em fins do século XIX - como Bairro Morro Azul e fazia parte da Fazenda Monte Alegre, de propriedade do tenente-coronel Vicente Gonçalves da Silva, que a herdara de familiares (Martins, 1986, p. 685).

Em 1868, o tenente-coronel Vicente Gonçalves da Silva casou-se com Francisca Tomázia - carinhosamente chamada de Chiquinha Ramos - e eles passaram a morar na Fazenda Morro Azul. Segundo consta, dona Chiquinha era mulher religiosa e os últimos anos de sua existência "foram consagrados ao bem" (E.E.P.S.G. Profa. Joanna Di Felippe, 1998, p. 12). ${ }^{10}$

Dona Chiquinha batizou cerca de 530 crianças, as quais buscava acompanhar nas várias fases da vida. Essa religiosidade alcançou maior expressividade quando ela passou a se preocupar com colonos e conhecidos que tinham problemas de vista. Na ânsia de ajudá-los, dona Chiquinha dedicou-se às orações e à devoção a Santa Luzia, a santa protetora dos olhos e da visão.

O marco da devoção a Santa Luzia ocorreu em 1908, com a chegada da imagem da santa em sua residência (E.E.P.S.G. Profa. Joanna Di Felippe, 1998, p. 15).

São muitas as versões sobre a chegada da santa ao bairro. Entre elas, está a de que dona Chiquinha, após tornar-se grande devota de Santa Luzia, encomendou a familiares que estavam na Itália uma imagem da santa para colocá-la em sua residência na Fazenda Morro Azul. Entretanto, segundo depoimento de sua neta Francisquinha, a imagem foi um presente enviado por sua filha Clara e seu genro, dr. Nésio (médico oftalmologista e especialista em catarata), que residiam na Itália (E.E.P.S.G. Profa. Joanna Di Felippe, 1998, p. 16).

A imagem, feita em biscuit, tinha tamanho natural e, por tal razão, não foi possível a dona Chiquinha colocá-la no oratório de seu quarto. Ela, então, não poupou esforços para construir uma capela para a santa (E.E.P.S.G. Profa. Joanna Di Felippe, 1998, p. 16).

A construção da capela ficou a cargo de dois filhos de imigrantes italianos da família Cavalheiro, que moravam nas proximidades da

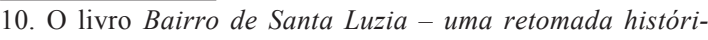
ca e uma visão atual foi um trabalho elaborado e dirigido por professoras da E.E. P. G. Profa. Joanna Di Felippe, com a participação dos alunos da educação infantil e do ensino fundamental como forma de resgatar a história do bairro e preservá-la.
} 
Fazenda Morro Azul, no Bairro Alto Alegre. O espaço da capela comportava "umas trinta pessoas em pé, sendo que na entrada existia um espaço reservado para o coro". Foi ornamentada com mosaicos brancos e pretos e um altar em madeira - onde foi colocada a imagem de Santa Luzia (E.E.P.S.G. Profa. Joanna Di Felippe, 1998, p. 17).

A capela, internamente, compunha-se de um altar com uma imagem do Espírito Santo rodeada "por um balaústre entalhado de madeira, castiçais enormes e dourados, o lustre de madeira suspenso por uma corda; nos vitrôs, vidros coloridos e o teto forrado de madeira". ${ }^{11}$ Para se chegar até ela, havia "uma estradinha" que levava a "um portão de madeira com um enorme cadeado de ferro". A capela era "ladeada por coqueiros e um coreto de chão de madeira", que ficava a poucos metros do templo (E.E. P.S.G. Profa. Joanna Di Felippe, 1998, p. 18).

Antes de inaugurá-la, em 1909, dona Chiquinha Ramos organizou uma grande festa, que contou com a participação de músicos e uma novena em louvor a Santa Luzia. No ano seguinte, em 1910, no dia 13 de dezembro (data em que se comemora o dia de Santa Luzia) foi celebrada a primeira missa pelo padre Landel de Moura, então pároco da cidade. Na cerimônia, estavam presentes os proprietários da Fazenda Morro Azul, seus familiares e colonos italianos.

A partir dessa data, a festa tornou-se tradição no bairro, sendo realizada, nos anos seguintes, por d. Chiquinha e suas filhas, com a colaboração dos imigrantes italianos e outros moradores da Fazenda Morro Azul (E.E.P.S.G. Profa. Joanna Di Felippe 1998, p. 19).

Em 1915, após a morte de d. Chiquinha Ramos, a Fazenda Morro Azul foi dividida por um de seus filhos, o sr. Aureliano Gonçalves da Silva. Com o tempo, tais propriedades foram sendo vendidas para os colonos italianos que lá haviam se fixado. ${ }^{12}$ Estes passaram a desen-

11. Depoimento do sr. Delelmo Paganini, um dos pedreiros responsáveis pela demolição da capela para a construção da igreja atual. In: E.E.P.S.G. Profa. Joanna Di Felippe, 1998, p. 20 .

12. Entre as famílias italianas que se fixaram na região citamos: Palermo, Ricci, Ragazzo, Bertoldo, Fadini, Paganini, Belli, Turati, Miglioni, Angeloti, Monferdini, Rúpolo, Lago, Passarelli, Bianchi, Risseto etc. In: Tamaso, 2005b, p.44 volver a agricultura familiar, voltada para o autosustento e a produção de café.

A igreja, nos anos 50, foi demolida para a construção da atual, que continua abrigando a imagem original e, junto dela, as imagens de Nosso Senhor Jesus Cristo Crucificado e da Virgem Maria. Tal construção foi adornada com pinturas feitas por descendentes de italianos moradores do bairro e contou com a ajuda financeira de grande parte da comunidade luziana. ${ }^{13}$

\section{Os lugares entre práticas e representa- ções}

Os espaços sociais edificados pelos negros e italianos e seus descendentes em Pinhal foram investigados contemplando-os como "construções simbólicas" carregadas de significados específicos intrinsecamente relacionados às práticas que tais grupos vêm experimentando desde fins do século XIX na cidade.

Compreender tais construções como simbólicas exigiu que adentrássemos no microcosmo da cultura e da história, tarefa que nos levou a perceber tais construções como representação do mundo vivido - normatizado, regulado, moldado e espacializado de acordo com os interesses e jogos do poder (Roger Chartier, 1982).

As práticas experienciadas por sujeitos históricos nesses espaços foram, portanto, analisadas em contextos específicos próprios, por meio dos quais identificamos os espaços socioculturais construídos pelos diversos grupos étnicos em Pinhal. Como afirma Ana Fani A. Carlos (1996, p. 25-37), são as relações sociais que garantem "a construção de uma rede de significados e sentidos que são tecidos pela história e cultura civilizadora produzindo a identidade. Aí o homem se reconhece porque aí vive".

Quando falamos em identidade, estamos nos remetendo àquele conceito de identidade como algo historicamente construído, o que Stuart Hall (2004, p.13) denomina de "celebração móvel", "formada e transformada continuamente em relação às formas pelas quais somos

13. Expressão criada por mim para denominar a comunidade italiana e seus descendentes moradores do Bairro de Santa Luzia. Sobre isso ver: Tamaso, 2005b, p.69. 
representados ou interpelados nos sistemas culturais que nos rodeiam". Por identidade, entendemos o laço que une indivíduos, seja ele religioso, fenotípico, étnico, político, econômico, de raça etc. A identidade revela e esconde características essenciais ao indivíduo ou grupo. Mas, para compreendê-la, faz-se necessário desvendar os véus que cobrem o "drama social". ${ }^{14}$

A questão da identidade em nossa análise remete, portanto, a uma afirmação não apenas étnica, mas principalmente indiciária com o lugar, como nos propôs Carlo Ginzburg (1990). Para analisarmos um determinado signo, há de se fazer uma análise das práticas que o constituíram e das suas representações para os diversos sujeitos históricos.

Dessa forma, pensar em identidade pressupõe conceber algo que foi construído por sujeitos históricos e que os representa perante os "seus" e os "outros". Para entendermos a identidade, temos de nos aventurar no estudo da história, das tradições e das representações nas quais tal signo foi construído. Tal qual na análise sobre a cultura, o caráter dinâmico da identidade vem da relação direta que esta estabelece com os indivíduos em suas sociedades, ou seja, na interação estabelecida entre os homens, o espaço físico e o espaço social.

Assim, como nos propõe Ana Fani Carlos (1996, p.29), o sujeito pertence ao lugar como este a ele, "pois a produção do lugar se liga indissociavelmente à produção da vida". Para ela, no lugar emerge a vida, "posto que é aí que se dá a unidade da vida social". Assim afirma:

[...] o lugar é, em sua essência, produção humana, visto que se reproduz na relação entre espaço e sociedade, o que significa criação, estabelecimento de uma identidade entre

\footnotetext{
14. O conceito "drama social" foi desenvolvido por Victor W. Turner (1957) em Schism and continuity in an African society. A noção de "drama social" possibilitou a Turner o "estudo da estrutura dos sucessivos eventos no processo social", buscando ver como as "tendências sociais operam na prática". Da mesma forma, utilizando tal conceito, buscamos, por meio das práticas sociais estabelecidas no espaço urbano pinhalense, refletir sobre a ordenação espacial e os conflitos que, a partir dela, surgiram. Temas como identidade, etnicidade e a construção de espaços étnicos na cidade de Pinhal foram trabalhados em minha tese de doutoramento. Tamaso, 2005a.
}

comunidade e lugar, identidade essa que se dá por meio de formas de apropriação para a vida. (Carlos, 1996, p. 29)

O historiador Michel de Certeau (1994, p. 57) entende o espaço como "um lugar praticado", "um cruzamento de forças motrizes", um lugar que é produto das relações humanas, que foi tecido por relações sociais dadas no plano do vivido. Ou seja, o lugar é entendido como um espaço físico socialmente e culturalmente constituído por códigos, signos e sistemas de símbolos, por redes que são tecidas em tempo e espaços específicos.

Nessa perspectiva, assim como o Largo de São Benedito é lugar dos negros e afrobrasileiros, o Bairro de Santa Luzia é reconhecido como o espaço dos italianos na cidade de Pinhal. Lugar da práxis, é no espaço físico concreto - e social - real - que o sujeito "se reconhece ou se perde, usufrui e modifica, posto que o lugar tem usos e sentidos em si" (Carlos, 1996, p.29). Tais usos e sentidos são representações de sonhos e práticas, de estratégias e táticas (De Certeau, 1994, p. 58).

A construção da Igreja de São Benedito representa tais práticas que reforçam a necessidade de afirmação de uma identidade negra em um espaço legitimamente branco, ainda que impuro (dada a presença anterior do cemitério), constituindo para aqueles negros uma "resistência à lei histórica", na concepção de De Certeau (1994, p. 79).

A Igreja de São Benedito, contida no Largo de Benedito, revelou-se um espaço no qual se combinaram, como propôs Carlos R. Brandão (1985, p. 17), a propósito da Festa de Nossa Senhora do Rosário em Catalão, "diferentes ordens e categorias de pessoas e de grupos, assim como trocas de atuações entre eles". Significa dizer que, ali no espaço onde o negro e o afro-brasileiro materializaram signos de sua identidade étnica, também puderam, por intermédio da Igreja de São Benedito, estabelecer as trocas simbólicas com outros grupos étnicos da cidade. Trocas que se efetuaram em meio às manifestações culturais em nome do santo preto.

Com relação à Igreja da Santa Luzia, apesar de também ser um lugar reconhecidamente dos 
brancos, ela não foi incluída nos espaços de poder legitimados pela elite branca lusobrasileira. Assim como os negros, os italianos e seus descendentes foram excluídos dos melhores espaços e lugares. A eles foi limitada a participação política, já que eram imigrantes.

Tais condições não os impediram, entretanto, de deixar suas marcas nas áreas econômicas e culturais da cidade. Juntamente com os italianos, veio o desenvolvimento do comércio de secos e molhados, ferragens e das indústrias de máquinas, pastifícios e móveis. Segundo Tamaso (1998), os italianos foram os grandes artífices de esculturas, pinturas, entalhes em madeira ainda presentes em várias igrejas da cidade e de construções destinadas à encenação de óperas, apresentações de saraus e, posteriormente, cinemas. De acordo com ela, aos italianos pode ser atribuída parte da construção do patrimônio edificado de Espírito Santo do Pinhal (Tamaso, 1998, p. 152)

Com relação aos negros, devido às estratégias de ordenação e normatização, não conseguiram colocação de destaque, passando a ocupar funções domésticas ou de menor importância em órgãos públicos, como telegrafista dos Correios, por exemplo. ${ }^{15}$ Suas manifestações culturais, entretanto, marcaram a história da cidade e continuam representadas pelos grupos musicais de samba e no carnaval, com a apresentação do Grêmio Recreativo Bangú.

\section{Manifestações de fé e de identidade}

Assim como o espaço das igrejas, as festas relacionadas aos santos padroeiros constituíram momentos em que manifestações de fé e devoção transformaram-se em lugares de afirmação de identidades étnicas.

As festas religiosas - do final do século XIX e início do século XX - eram organizadas por grupos ligados a etnias específicas - lusobrasileira, italiana ou ítalo-brasileira, negra e afrobrasileira entre outras -, que buscavam por meio dessas manifestações se colocar no espaço

15. José Amaro de Oliveira trabalhou muitos anos como telegrafista dos Correios da agência de Pinhal. Sua foto figura entre os funcionários dessa instituição no ano de 1949. In: Poliantéia. Revista do Centenário de Espírito Santo do Pinhal/SP. Espírito Santo do Pinhal: s/ed., 1949. político e sociocultural local. As Festas de São Benedito e Santa Luzia são duas dessas manifestações que representam o lugar da fé das comunidades negra, afro-brasileira e italiana na cidade de Pinhal.

A relação festa-religião foi, exaustivamente, pesquisada e analisada em diversos contextos histórico-sociais. E. Durkheim (1989, p. 456) observou que a própria idéia de cerimônia religiosa de alguma importância desperta, naturalmente, a idéia de festa. Sua análise proporciona a elucidação entre sagrado e profano.

Jean Duvignaud (1983) é outro teórico importante nos debates sobre festa. Contudo, não obstante tratar do sagrado e do profano nos moldes ditados por E. Durkheim (1989), dele vai se distinguir, bem como de Mircea Eliade (2002) e de Roger Caillois (1978), pelo fato de negar o caráter de funcionalidade atribuído às festas.

A festa, para J. Duvignaud (1983, p. 25), não deve ser reduzida ao caráter de utilidade, caso contrário corre-se o risco de perder de vista a sua capacidade subversiva, uma vez que "a vida coletiva é realizada com o imprevisível e o inelutável e que a experiência comum faz romper em fragmentos, no tempo e no espaço, as belas construções unitárias, estruturais ou funcionais". Após as festas, restam as inquietações criadoras das mudanças sociais.

A historiadora Martha Abreu aponta dois grandes desafios para quem se ocupar em estudar as festas. Segundo ela, é necessário:

[...] pensar os significados e mudanças das festas em sua própria historicidade, mas, sobretudo, compreender a dinâmica relação das festas com a existência dos homens e mulheres que as tornaram, em qualquer época e local, autênticas e concorridas. (Abreu, 1999, p. 38)

Nesse contexto, as Festas de São Benedito e Santa Luzia são, sem dúvida, uma manifestação sociocultural significativa no contexto histórico da cidade de Pinhal. Como nos propõe Natalie Davis (1990, p. 87), além de funcionar como perpetuação de valores caros à comunidade, garantindo sua sobrevivência, tais manifestações podem servir como instrumento de crítica à ordem social vigente. 
Analisadas a partir dessa última perspectiva, as festas religiosas em Pinhal - com exceção da Festa do Divino, que vem sendo recuperada há apenas alguns anos -, além de serem compreendidas como manifestação da devoção nesses santos, devem, também, ser analisadas como representação de tradições vindas juntamente com a chegada de negros alforriados e imigrantes (portugueses, italianos e espanhóis) na cidade de Pinhal. São nesses lugares que o elemento de identidade étnica se expressa com toda força e vigor, unindo, em um mesmo espaço físico, universos sociais e simbólicos diferentes.

Por isso mesmo, a importância de tais manifestações é também relativa. Quando observadas por quem é de fora da comunidade, por quem não pertence a ela, ou por quem não mantém laços de identidade com ela, tais festas adquirem uma importância, às vezes, muito diversa daquela que a própria comunidade the atribui (Barreto, 2001).

Segundo De Certeau (1994), quando analisamos as práticas sociais de um outro, devemos compreendê-las engendradas em um universo particular construído em meio a valores e princípios morais próprios a ele, e que, portanto, não devem ser desprezados nem nas falas nem nos silêncios.

Não podemos esquecer que, para Todorov (1993, p. 250), ao descobrirmos o outro, descobrimos um pouco de nós mesmos, um outro eu. Buscando a igualdade, encontramo-nos nas diferenças. O importante, para ele, é viver a diferença na igualdade.

[...] Queremos a igualdade sem que ela acarrete a identidade; mas também a diferença, sem que ela degenere em superioridade/inferioridade; [...] aspiramos à recuperação do sentido do social, sem perder a qualidade do individual. (Todorov, 1993, p. 250)

Ainda hoje, ao longo de todo o ano, as diversas comunidades se organizam em seus bairros e realizam festas em homenagem aos santos padroeiros. Entretanto, as que mais se destacam são as do Divino Espírito Santo, na Praça da Matriz, de São João, no Largo de São João, de São Pantaleão no Alto Alegre, e de Santa Luzia.
A festa em louvor a São Benedito ocorreu durante pelo menos oitenta anos, sobrevivendo até os anos 80 do século XX. Quando deixou de existir, passou a confirmar a perda não somente dos valores caros a seu grupo, mas, sobretudo, sua desorganização e fragmentação diante de imposições feitas pelos grupos dominantes da cidade, principalmente a Igreja local. As palavras de afro-brasileiros são representativas do ressentimento em função do desaparecimento da festa:

Mas acabou tudo né... Acabou até as festas de São Benedito... O padre acabou né... Agora é lá na praça. ${ }^{16}$ (Grifo meu)

O desaparecimento da Festa de São Benedito não apagou, contudo, as memórias tanto de pretos como de brancos, que não se cansam de lembrar que a cidade ficava coberta por poeira, que se levantava ao som dos tambores do samba e da dança das "moças da vida", manifestações do profano. Em função disso, surgiu a frase: "Levanta a poeira São Benedito!".

No seu contraponto, a Festa de Santa Luzia continua ocorrendo todos os anos, desde 1909, no Bairro de Santa Luzia. Por meio das tradições orais, os italianos e seus descendentes buscam manter vivas as memórias, os costumes, as práticas cotidianas e a devoção a Santa Luzia.

A festa se realiza todos os anos no dia 13 de dezembro, e a comunidade luziana não falta às missas, procissões, alvoradas, quermesses e aos leilões que fazem parte das manifestações de fé a Santa Luzia. Um dos momentos mais esperados pela comunidade é o da matança dos leitões, que ocorre sempre uma semana antes do início da festa.

A organização da festa fica a cargo de uma comissão escolhida em uma eleição bienal. Tal comissão é composta, em sua maioria, de descendentes de italianos, que não poupam esforços para torná-la cada vez mais digna das graças que a santa lhes concede. Dessa forma, a comunidade organiza um evento que reúne,

\footnotetext{
16. D. Nena refere-se à Praça da Matriz do Divino Espírito Santo, local onde ocorrem as festas em celebração ao Divino Espírito Santo, organizadas pelo monsenhor Augusto, a quem ela chama de "padre". D. Nena (Helena Fernandes), afro-brasileira, foi moradora do Largo de São Benedito. In: Tamaso, 2005a, p.251.
} 
todos os anos, mais de trinta mil fiéis em devoção à santa protetora dos olhos.

A continuidade da Festa de Santa Luzia pode ser explicada considerando as especificidades da comunidade luziana. Diferentemente dos negros e de seus descendentes, as relações estabelecidas entre as famílias italianas passaram de laços de solidariedade e de parentesco às relações de compadrio (Tamaso, 1995, p.08). Muitos casais começaram a batizar e a apadrinhar em matrimônio sobrinhos e sobrinhas. Irmãos passaram a se casar com irmãs de outras famílias, preservando assim as terras entre si. ${ }^{17}$

Segundo Tamaso $(1995$, p. 8), essas alianças fundamentaram não somente "o princípio básico de reafirmação de parentesco", mas também foram essenciais para "a relação com a propriedade". Para ela, na Santa Luzia, o sistema de parentesco e de compadrio foi responsável pela manutenção das propriedades entre famílias e da sua união como grupo étnico e social.

No seu revés, apesar de os negros virem sofrendo com o esfacelamento de sua unidade familiar desde os tempos coloniais e de Robert Slenes (1999, p. 49) ter demonstrado que a constituição de uma "família cativa", em muitos lugares, estreitou os laços entre os negros e colaborou para a formação de uma identidade, podemos aventar que as sucessivas uniões conjugais com brancos (italianos e espanhóis) enfraqueceram ainda mais a unidade dos negros como grupo étnico e cultural.

As relações entre negros e italianos foram muito mais intensas do que as relações entre os primeiros e os luso-brasileiros. Essa característica possibilitou a criação entre aqueles de inúmeros laços, profissionais, matrimoniais, de amizade ou solidariedade. No espaço urbano, tais grupos passaram a dividir não apenas espaços físicos, como também sentimentos de diferença e exclusão. Apartados do espaço urbano da elite, negros e italianos buscaram fixar-se em regiões de entrada e saída da cidade

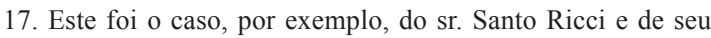
irmão Antônio Ricci, que se casaram com as irmãs Eunice e Zoraide Belli. Outros casos podem ser citados, como das famílias Palermo e Ragazzo, que também constituíram alianças com as famílias Belli e Ricci. In: Tamaso, 1995, p. 10 ou separadas por barreiras físicas, como o Ribeirão da Quaresma, Ribeirão dos Porcos e Maria Joaquina.

Tal argumento ganha força quando analisamos a Festa de São Benedito. Desde seus primeiros anos, observamos que ela nunca foi lugar exclusivo de negros e afro-brasileiros. $\mathrm{Na}$ verdade, tal manifestação representava o momento em que as regras eram quebradas e as normas eram burladas, sob os olhos atentos e vigilantes do santo. Da festa faziam parte negros e seus descendentes e brancos-luso-brasileiros, italianos e espanhóis -, que rezavam e festejavam suas semelhanças e diferenças.

No "momento festivo"18 tais transgressões são aceitas, já que permitem aos homens não ver suas diferenças, sejam elas econômicas, sociais, culturais ou étnicas. Como afirmou Carlos R. Brandão:

Os rostos do trabalho mudam na festa.

Mudam nela e para ela.

[...] Os homens do trabalho, brancos, negros, camponeses, operários, por uma tarde, por um dia, por dois ou três, são guerreiros mouros ou cristãos.

[...] pois na festa as pessoas cobrem o rosto de máscaras, de fitas e de tintas.

Cobrem o rosto dos sinais de festa, para descobrirem, no disfarce fugaz, a face verdadeira de quem são, quando sonham ser. (Brandão, 1998, p. 61, grifo meu)

O "disfarce fugaz" que o momento festivo permite acaba por encobrir as diferenças, transformando os sujeitos em personagens daquilo que gostariam de ser, representando fantasias, vivenciando e experienciando formas de manifestar seus desejos e suas frustrações. É no momento festivo que as diferenças desaparecem, funcionando como catalisador para a participação de grupos sociais e étnicos diferentes nas manifestações culturais da cidade.

Assim como na construção da Igreja de São Benedito e na festa em seu louvor, também na edificação da Igreja de Santa Luzia e nos festejos à santa os elementos étnicos de negros e italianos misturam-se. Da mesma maneira que os brancos

18. Expressão utilizada por Maria Cristina Silva em seu estudo sobre a Festa de São Benedito em Aparecida. Silva, Maria C. Viva São Benedito... São Paulo: 2000. 
participaram da construção do templo ao santo negro, negros participam dos festejos à santa branca.

A festa brasileira, segundo Rita Amaral (1998, p. 109), ao mesmo tempo nega e reitera o modo de vida como a sociedade se organiza, selecionando o que deve ser "relegado ao esquecimento; o que deve ser transformado e o que deve permanecer". Para ela,

A festa brasileira se apresenta, então, como mediação privilegiada entre dimensões e estruturas várias, unindo o passado ao presente, o presente ao futuro, a vida e a morte (nas festas comemorativas de eventos históricos, por exemplo), o sagrado e o profano, a fantasia e a realidade, o simbólico e o concreto, os mitos e a história, o local e o global, a natureza e a cultura. (Amaral, 1998, p. 109)

Apesar de o nosso recorte temporal estar bem distante do período colonial sobre o qual Del Priore se deteve, as festas aqui analisadas revelam que, apesar de a elite e a Igreja tentarem interferir de formas variadas na sociabilidade local, a festa criou "brechas de resistências, transculturalidades e utopias" que somente o momento festivo permite.

Ritos e crenças, danças e cantos, homens e santos, sagrado e profano misturam-se em um amálgama que somente o momento festivo possibilita. A participação da Congada de São Benedito, da cidade de Mogi Guaçu, na Festa de Santa Luzia no ano de 2003 pode ser um indício da transgressão de normas e possivelmente da utilização de táticas - por parte dos negros - para adentrar em espaços "outros", que não os legitimamente escolhidos e determinados como "seus".

A retirada da antiga imagem do "santo preto" da Igreja de São Benedito também reforça a idéia de expropriação sofrida pelos negros e afro-brasileiros ao longo de sua história, pois, além de serem continuamente apartados de seus familiares, o foram também de seus signos.

Cabe lembrarmos que o processo de romanização ${ }^{19}$ por que passou a Igreja brasileira a

19. Segundo Lilia Medrano, "Romanização foi o nome dado, no Brasil, para as reformas promovidas por Pio IX com o objetivo de reforçar a autoridade do Papado, que vinha se partir da segunda metade do século XIX determinou as mudanças observadas nas práticas religiosas, principalmente nos núcleos urbanos. Segundo Lilia Inês Z. de Medrano (2005, p. 325), a paróquia "passou a ser o lugar de articulação da hierarquia eclesiástica com o povo, tendo como mediador o pároco, agora fortalecido em sua prática pastoral e política". Portanto, fez-se necessário aumentar o número de paróquias e criar novas dioceses. Dessa forma, oficializavase, institucionalizava-se e hierarquizava-se a Igreja no Brasil, antes dominada pelas práticas religiosas populares, ligadas à comunidade e a familiares.

Todavia, à luz da realidade brasileira, a romanização adquire um perfil singular. Segundo Lilia Medrano (2005, p. 385), a paróquia incorpora tanto as instituições religiosas leigas como a religiosidade popular, afastando-as da mediação sagrada e "substituindo as devoções dos santos populares brasileiros por uma devoção do catolicismo centrado em Roma". O cumprimento dos sacramentos, especialmente o do matrimônio, começa a ser exigência aos crentes. E, ainda, as capelas e oratórios "passaram a ser submetidos à autoridade paroquial", o vigário e os santuários outrora dedicados à devoção popular "passaram a ser administrados pelo clero regular".

Nesse sentido, a retirada da imagem de São Benedito, o deslocamento de práticas consideradas profanas (pela Igreja oficial) para fora do espaço sagrado, assim como outras ações institucionais podem ser explicados por meio da análise do processo de romanização implementado no Brasil nessa época.

Mais uma vez, fica atestado o papel normatizador das instituições de poder - como a Igreja em Pinhal -, que, privilegiando o patrimônio do Divino Espírito Santo em detrimento do patrimônio de São Benedito, buscou

\footnotetext{
desgastando desde a cisão da cristandade no século XVI, após a Reforma Protestante, seguida da ascensão das monarquias absolutistas, a laicização e depois a racionalização do pensamento, as revoluções liberais e a consolidação do capitalismo no século XIX. Tratava-se de desenvolver esforços no sentido de reformulação política e administrativa voltadas para a ampliação do poder de Roma sobre questões de liturgia, disciplina e nomeações, além de valorização e veneração da pessoa do Papa e o reestabelecimento do óbolo de São Pedro" (2005, p. 403)
} 
construir estratégias de exclusão e dominação, assegurando, dessa forma, a ordem pretendida por tais instituições e seus representantes, nos diversos espaços - tanto públicos como privados (Del Priore, 2000, p. 90).

Outro argumento que comprova a constituição de táticas por parte dos grupos estudados - negros e italianos, ambos excluídos -, para assegurar seu lugar nos espaços da cidade, é a participação da Paróquia de São Benedito na Festa de Santa Luzia. Na missa de abertura da Festa de Santa Luzia no ano de 2005, estavam colocadas no altar principal, junto à imagem da santa italiana, as imagens de Nossa Senhora Aparecida e São Benedito (santos reconhecidamente negros). Será que podemos considerar tal ação como "norma" ou mais uma tática utilizada pelos grupos étnicos - negros ou italianos - para driblar as estratégias de poder?

Será que não estamos aqui diante da constatação de que o elemento religioso é ao mesmo tempo excludente - ao determinar espaços para o sagrado e profano - e inclusivo - quando possibilita a participação de "um outro" dentro do "seu próprio"?

Em Pinhal, assim como em tantos outros locais do país, é nas manifestações festivas que lugares negros e brancos diluem-se, rompendo, mesmo que momentaneamente, os limites impostos pela ordem - apesar das estratégias utilizadas para apartá-los, as táticas os uniram na exclusão. Sob a proteção dos santos, os homens - brancos, negros ou mestiços - ultrapassam as linhas tênues, mas reais, que os separam: o preto e o branco só compõem o cinza na poeira dos festejos ou na cegueira dos santos e dos homens.

\footnotetext{
Abstract: The religiosity has been showed as fundamental element to understand the inter-ethnic relationships in different spaces, social territorial and political, in the town Espírito Santo do Pinhal (São Paulo) from its foundation to nowadays. Religiosity as cultural manifestation was a way to ocaupy the political, social, and altural space among the different ethnic groups. It was the way to include or exclude in the urban space of these town. The churches of "São Benedito" and "Santa Luzia" are two representative places for black people, Afro-descendents and Italian-descendents, therefore, these places are analyzed as identify signs. Through them, and the
}

manifestations there, the intention is analyse the used "tatics", "strategies" and "practices" from different ethnic groups to consolidate their place in the town, but above all, to confirm their identities.

Key-words: religiosity; sacred; profane; ethnic identity; altural manifestation.

\section{Referências}

ABREU, Martha. O império do Divino. Rio de Janeiro: Nova Fronteira/São Paulo: Fapesp, 1999.

AMARAL, Rita de C. A alternativa da festa à brasileira. Revista Sexta-Feira, ano 2, vol. 2. São Paulo: Pletora, 1998.

ARQUIVO DA CÂMARA MUNICIPAL DE ESPÍRITO SANTO DO PINHAL. Livros de Atas de Sessões Ordinárias e Extraordinárias. Anos de 1868 a 1930.

BARRETO, Margarita; BANDUCCI, Álvaro. Turismo $e$ identidade local - uma visão antropológica. Campinas/SP: Papirus, 2001.

BRANDÃO, Carlos R. A festa do santo preto. Rio de Janeiro: Funarte/Instituto Nacional do Folclore; Goiânia: Universidade Federal de Goiás, 1985.

O rosto da festa. Revista Sexta Feira, ano 2, v. 2, p. 61. São Paulo: Pletora, 1998.

CAILLOIS, Roger. O homem sagrado. Trad. Geminiano Cascais Franco. Lisboa: Ed. Setenta, 1978.

CARLOS, Ana Fani A. O turismo e a produção do não-lugar. In: YÁZIGI, E.; CARLOS, Ana F. A.; CRUZ, Rita C. A. (Orgs.). Turismo - Espaço, paisagem e cultura. São Paulo: Hucitec, 1996. p. 2537.

CHALHOUB, Sidney. A guerra contra os cortiços cidade do Rio, 1850-1906. Primeira Versão, n. 19. Campinas: IFCH/Unicamp, 1990.

CHARTIER, Roger. A história cultural - entre práticas e representações. Trad. Maria Manuela Galhardo. Lisboa: Difel, 1982.

DARNTON, Robert. O beijo de Lamourette - mídia, cultura e revolução. Trad. Denise Bottmann. São Paulo: Companhia das Letras, 1986.

. O grande massacre de gatos. Rio de Janeiro: Graal, 1986.

DAVIS, Natalie. Culturas do povo. Rio de Janeiro: Paz e Terra, 1990.

DE CERTEAU, Michel. A invenção do cotidiano: 2. Morar, cozinhar. Tradução de Ephraim Ferreira Alves e Lúcia Endlich Orth. Petrópolis/RJ: Vozes, 1998.

A invenção do cotidiano: Artes de fazer.

Tradução de Ephraim Ferreira Alves. Petrópolis/RJ: Vozes, 1994. 
DEL PRIORE, Mary. Festas e utopias no Brasil Colonial. São Paulo: Brasiliense, 2000.

DURKHEIM, Émile. As formas elementares da vida religiosa: o sistema totêmico na Austrália. Tradução de Joaquim Pereira Neto. São Paulo: Ed. Paulinas, 1989.

DUVIGNAUD, Jean. Festas e civilizações. Tradução e Nota Introdutória de L. F. Raposo Fontenelle. Fortaleza/CE: Ed. Universidade Federal do Ceará; Rio de Janeiro: Tempo Brasileiro, 1983.

E.E.P.S.G. PROFA. JOANNA DI FELIPPE. Bairro de Santa Luzia - uma retomada histórica e visão atual. Espírito Santo do Pinhal/SP: Gráfica Mário L. Bazani, 1998.

ELIADE, Mircea. Tratado de história das religiões. Tradução de Fernando Tomaz e Natális Nunes. São Paulo: Martins Fontes, 2002.

GEERTZ, Clifford. O saber local. 5. ed. Petrópolis/ RJ: Vozes, 1997.

. A interpretação das culturas. Rio de Janeiro: Ed. Guanabara Koogan, 1989.

GINZBURG, Carlo. Mitos, emblemas, sinais morfologia e história. Tradução de Federico Carotti. São Paulo: Companhia das Letras, 1990.

GODOI, Emília P; NIEMEYER, Ana M. (Orgs). Além dos territórios - para um diálogo entre a etnologia indígena, os estudos rurais e os estudos urbanos. Campinas/SP: Mercado das Letras, 1998.

HALL, Stuart. A identidade cultural na pós-modernidade. Tradução de Tomaz Tadeu da Silva e Guaracira Lopes Louro. 9. ed. Rio de Janeiro: DP\&A, 2004.

LESSER, Jeffrey. A negociação da identidade nacional - imigrantes, minorias e a luta pela etnicidade no Brasil. Tradução de Patrícia de Queiroz Carvalho Zimbres. São Paulo: Editora Unesp, p. 2001.

MARTINS, Roberto V. Divino Espírito Santo e Nossa Senhora das Dores do Pinhal: História de Espírito Santo do Pinhal. São Paulo: Impr. Latina, 1986.

MEDRANO, Lilia Inês Z. A criação da diocese de Campinas no contexto histórico. Arquidiocese de Campinas: subsídios para a sua história. Campinas: Ed. Komedi, 2005.

O PINHALENSE. Periódico. Coleção (1906 a 1921) da Biblioteca Municipal Dr. Abelardo V. César, em Espírito Santo do Pinhal.

POLIANTÉIA. Revista do Centenário de Espírito Santo do Pinhal/SP. Espírito Santo do Pinhal: s/ed., 1949.
POUTIGNAT, Philippe; STREIFF-FENART, Jocelyne. Teorias da etnicidade - seguido de grupos étnicos e suas fronteiras de Fredrik Barth. Tradução de Elcio Fernandes. São Paulo: Editora Unesp, 1998. RIZZONI, Ernesto. Pinhal: história em notícia. Espírito Santo do Pinhal/SP: s/ed., s/d.

SILVA, Maria Cristina. Viva São Benedito... São Paulo: s/ed., 2000.

SLENES, Robert. Na senzala, uma flor - esperanças e recordações na formação da família escrava. São Paulo: Companhia das Letras, 1999.

TAMASO, Izabela M. Tratorando a história percepções do conflito na prática da preservação do Patrimônio Cultural edificado em Espírito Santo do Pinhal. Brasília, 1988. Dissertação (Mestrado) UnB.

Santa Luzia: de olhos no compadrio. Brasília, 1995. Trabalho de conclusão da disciplina Organização Social e Parentesco. Programa de PósGraduação em Antropologia Social do Departamento de Antropologia, UnB.

TAMASO, Renata M. Homens de cor, pretos e coloreds - A construção de espaços de sociabilidade dos afro-brasileiros e suas representações em Espírito Santo do Pinhal/SP (1890-1930). Assis (SP), 2005a. Tese (Doutorado) - Unesp.

. Turismo cultural e turismo religioso - Santa Luzia, olhai por nós! Proposta de requalificação da Festa de Santa Luzia em Espírito Santo do Pinhal/ SP. Águas de São Pedro/SP, 2005b. Monografia (Especialização em Planejamento e Marketing Turístico) - Senac.

Um cortiço chamado Brasil - Aluísio Azevedo e o Brasil do século XIX - uma leitura. Assis/SP, 1997. Dissertação (Mestrado) - Unesp.

TODOROV, T. A conquista da América - a descoberta do outro. São Paulo: Cortez, 1993.

TUAN, Yi-Fu. Espaço e lugar - a perspectiva da experiência. Tradução de Lívia de Oliveira. São Paulo: Difel, 1983.

TURNER, Victor W. Schism and continuity in an african society. Um study of Ndembu village life. Manchester University Press / University of Zambia / Institute for African Studies, 1957.

WOODWARD, Kathryn, Identidade e diferença: uma introdução teórica e conceitual. In: SILVA, Tomaz Tadeu da. (Org.) Identidade e diferença - a perspectiva dos estudos culturais. Petrópolis/RJ: Vozes, 2000. 
